\title{
ir
}

\section{CALDERÓN EN LA ESCENA Y EN LA IMPRENTA: PARA LA EDICIÓN CRÍTICA DE EL PRÍNCIPE CONSTANTE}

A Marc Vitse,

\author{
Luis Iglesias Feijoo \\ Universidad de Santiago de Compostela \\ [Anuario calderoniano (ISSN: 1888-8046), 1, 2008, pp. 245-268]
}

La Primera parte de comedias de don Pedro Calderón de la Barca apareció en las librerías de Madrid a mediados de julio de $1636^{1}$. La última de las obras ahí incluidas era El príncipe constante. Para tener una idea precisa de los pasos que hubo de dar el dramaturgo hasta editar la comedia y de las tareas que le fue necesario acometer, es preciso detenerse un momento en la preparación del conjunto del volumen ${ }^{2}$. Como es sabido, ningún autor de los que se movían entonces por la corte de España podía haber impreso teatro en Madrid en los años inmediatamente anteriores, pues el Consejo de Castilla había suspendido desde hacía casi una década la concesión de licencias para co-

\footnotetext{
${ }^{1}$ Este trabajo se enmarca en el Proyecto de investigación sobre la obra de Calderón financiado por la DGICYT HUM2004-03952, apoyado por el de la Xunta de Galicia PGIDT05PXIC20402PN. Ha sido decisivo el concurso de varios miembros del equipo, de los que debo citar a Santiago Fernández Mosquera, María Caamaño Rojo, Fernando Rodríguez-Gallego, Zaida Vila y Alejandra Ulla.

2 Dedico atención específica a la Parte primera en un trabajo en preparación.
} 
medias y novelas, sin que hubiera habido, que sepamos, una disposición específica al efecto ${ }^{3}$ : como sin la licencia no se podía publicar un libro, bastaba con no concederla para impedirlo. Era posible, desde luego, seguir estampando las partes que hubieran tenido permiso antes de 1625, lo que no era el caso de Calderón, entonces aún muy joven y casi en los inicios de su carrera. Cabía promover la edición en alguna de las ciudades del reino de Aragón, pues hasta allí no se extendía la jurisdicción de Castilla: así lo hizo Lope de Vega en el caso concreto de El castigo sin venganza, pero esa era una opción poco interesante para acometer la publicación de una Parte de doce comedias, y por ello, salvo Tirso o Alarcón, ninguno lo intentó y nuestro autor tampoco.

Tan pronto como el Consejo Real decidió reanudar la concesión de licencias para imprimir obras teatrales, lo que se llevó a cabo de manera tan inesperada como lo había sido la suspensión, los dramaturgos se apresuraron a recolectar sus textos para formar un tomo adocenado, según era la costumbre desde 1604, en que apareció la Parte inicial de las de Lope deVega. Parece ser que la primera solicitud otorgada tras la pausa de casi diez años le fue dada a Tirso de Molina el 8 de diciembre de 1634 para su Segunda parte. Es posible que ya en ese momento la nueva corriera como un cohete por mentideros, corrales, salones y academias, aunque el libro del mercedario no se publicó hasta fines de marzo de 1635; entonces sí que fue ya vox populi que las comedias tenían otra vez vía libre para pasar a los talleres. Curiosamente, la siguiente licencia conocida fue extendida el 8 del mismo marzo al propio Tirso, que pretendía editar otra Parte, la Cuarta, que lleva una aprobación del mes de enero anterior ${ }^{4}$. En mayo de este

3 Moll, 1974; Reyes Gómez, 2000, vol. I, pp. 292-303.

${ }^{4}$ Aunque Moll, 1974, p. 102, da ésta como la primera concedida tras la suspensión, ya constaba la fecha de diciembre de 1634 para la licencia de la Segunda parte en Cotarelo, 1906, p. lix; así lo rectifica el mismo Moll, 1992, p. 200; esa Segunda parte tiene aprobaciones de 10 y 20 de noviembre de 1634, momento en que el libro había sido, pues, recolectado y presentado a la autoridad: la fe de erratas es del 26 de marzo de 1635 y la tasa del día siguiente. Ver la reciente edición de esta parte en Tirso de Molina, Obras completas, p. 3. Con todo, se trata de un volumen bastante extraño, pues resulta insólito que en el prólogo el propio Tirso diga que de las doce comedias que ahí se incluyen, ocho no son suyas. Como es sabido, entre las comedias cuya autoría está en cuestión figura El condenado por desconfiado. La Cuarta parte del merce- 
año ya obtuvo otra el propio Lope, sólo tres meses antes de su muerte. No sabemos cuándo conoció Calderón la noticia, pero, dada su relación con los medios de la farándula, no pudo tardar mucho en hacerlo, fuese a finales de 1634, fuese con seguridad a partir del marzo siguiente, cuando el libro de Tirso salió de la imprenta, aunque su buena relación con el mercedario lleva a pensar que se debió de enterar muy pronto. No se olvide que el propio don Pedro redactó para el Consejo la aprobación de otra Parte del fraile, la Quinta, el 16 de julio de 1635.

Así pues, Calderón en seguida hubo de pensar en la conveniencia de reunir su teatro en volúmenes que consolidaran su prestigio. Llevaba quince años estrenando comedias, con general aplauso del público de los corrales y de la corte. Pero, en cambio, el reconocimiento del público lector resultaba imposible por la suspensión de licencias para imprimir en Castilla. Lope ya tenía tras de sí veinte Partes en 1625 y en 1635 saldrían a luz las dos siguientes; Calderón no podía publicar nada antes de ese último año. Y aún había algo peor, pues algunos impresores de la corona de Aragón aprovecharon la puerta que les había quedado abierta y empezaron a editar tomos de teatro, dando origen a la colección de "Diferentes», en los que se incluyeron varias obras suyas sin control alguno por su parte y, para mayor disgusto, atribuidas con bastante frecuencia a Lope de Vega: eso es lo que ocurrió en dos ocasiones con Amor, honor y poder, bajo el título de La industria contra el poder y el honor contra la fuerza; en otras dos con La devoción de la cruz, titulada La cruz en la sepultura; y también dos veces con La selva confusa, una de ellas con el título Selvas y bosques de amor. Pero, además de todas estas, también se prohijaron a Lope comedias suyas editadas sueltas - como, por otra parte, eran algunas de las anteriores, reunidas en una Parte de diferentes por el sistema de juntar una docena que habían aparecido en solitario-. Sueltas son, en efecto, dos ediciones distintas de La puente de Mantible y otra de La vida es sueño, las

dario estaba reunida al menos el 24 de enero de 1635, fecha de la remisión del vicario de Madrid a Juan Pérez de Montalbán para que informe; la aprobación pedida por el Consejo fue firmada por Lope de Vega el 10 de marzo; ver Cotarelo, 1906, pp. lxv-lxvi. Cabe recordar que la Tercera parte tirsiana había aparecido ya en 1634 en Tortosa. 
tres con el nombre de Lope de Vega como autor.Y aún circuló otra suelta de La cruz en la sepultura que la atribuía a Juan de Alarcón.

Ante esta situación, es comprensible el malestar de Calderón, que debió de llevarle a apresurar la recolección de los textos de sus obras a fin de componer volúmenes o partes que se imprimieran bajo su dirección. A principios de noviembre de 1635 había presentado ya al Consejo de Castilla el original de la primera, pues el 6 de ese mes de noviembre firma el informe favorable (la «Aprobación») Juan Bautista de Sossa (que casualmente era el esposo de su tía Juliana de Henao), y la remite a quien se la había solicitado, el vicario general de Madrid, Lorenzo de Iturrizarra, que extiende su licencia el 10 de noviembre. Con tales pronunciamientos favorables, a los que se suma la aprobación de Valdivielso del 23 de noviembre, pedida por el Consejo, este órgano extiende privilegio a favor de don Pedro Calderón el 10 de diciembre del mismo $1635^{5}$.

Debe subrayarse que es el propio don Pedro quien hace la solicitud de imprimir, por lo que son ociosas todas las consideraciones sobre si él estaba o no detrás de la publicación del volumen. Prescindamos ahora del curioso hecho de que desde el principio Calderón hubiese pensado en iniciar una serie de Partes, y no publicar un volumen aislado, pues la "Suma del privilegio» se lo concede para "poder imprimir por espacio de diez años un libro intitulado Teatro de comedias, primera parte». Hagamos también caso omiso de este curioso título, que acaso iba a ser el del libro en una intención inicial. Importa centrarse en la fecha mencionada en que de Sossa fecha su aprobación; ello quiere decir que hace unos días, sin duda pocos, que Calderón ha presentado su original al Consejo Real y Supremo de Castilla y éste ha dispuesto que el manuscrito pase al vicario general de Madrid para que emita el informe preceptivo. Iturrizarra delega en Sossa y, como vimos, éste firma su aprobación el 6 de noviembre de 1635. Por muy de prisa que hubiera ido todo el proceso, lo más probable es que Calderón entregase su original en los últimos días de oc-

${ }^{5}$ Aunque esto se trata con más detalle en el trabajo aludido en la nota 2, debe aclararse que el vicario acreditaba que no había reparo religioso en el libro, mientras que el Consejo de Castilla pedía por sí mismo otra información, que es la firmada por Valdivielso; obsérvese que éste la encabeza con la fórmula propia de respeto «M. P. S.» («Muy Poderoso Señor») y se dirige al Consejo con el tratamiento debido de «V. A.» («Vuestra Alteza»). 
tubre. Por lo tanto, desde que llegó a su conocimiento que la autoridad volvía a conceder licencias para imprimir teatro hasta ese momento habrían pasado entre seis y diez meses, dependiendo de la fecha en que conoció el primer permiso otorgado a Tirso. En cualquier caso, no era un tiempo excesivo para todo lo que tuvo que hacer antes de poder presentar el manuscrito.

Desde luego, lo primero que debe precisarse es que, contra lo que ingenuamente se pensaba hasta hace poco, este último no debía de ser un autógrafo. El Consejo y sus informantes no trabajaban con borradores llenos de tachaduras, como podemos pensar si evocamos algunos manuscritos teatrales autógrafos hoy conservados, que a veces pueden ser meros borradores, pero que, aunque se trate de copias en limpio, casi siempre revelan el proceso de acomodación que en pocos años el texto ha sufrido durante su vida escénica por parte de la compañía de actores. Y no cabe olvidar que las obras que nuestro autor iba a editar habían tenido su vida sobre los corrales. La autoridad administrativa no podía admitir tales manuscritos con columnas de versos tachados, atajos y tiradas enteras sustituidas por otras. Pero además la imprenta tenía que trabajar luego con ese mismo «original» ya aprobado, firmado o rubricado en cada uno de sus folios por el escribano de turno.

En efecto, dado el sistema existente en la época, que obligaba a «contar el original» antes de comenzar la impresión a fin de distribuir el texto en las páginas, los talleres recibían copias generalmente elaboradas por profesionales, caracterizadas por una regularidad constante en la composición de líneas y hojas que facilitaba la cuenta.Y aunque ésta era mucho más hacedera cuando se trataba de la composición de obras en verso, la necesidad de presentar al Consejo un original bien limpio y regular con el que luego habían de trabajar los regentes y cajistas seguía siendo la misma. El examen de los originales de imprenta hoy conservados ha llevado a Rico a una conclusión inequívoca $^{6}$ : en aquellos tiempos la «regla para las primeras ediciones era que la imprenta trabajara con una transcripción realizada por un amanuense contratado al efecto» ${ }^{7}$.

${ }^{6}$ Rico, 2005, p. 55.

${ }^{7}$ Ver completos los dos primeros capítulos del libro de Rico, «Cómo se hacía un libro en el Siglo de Oro» y «Del borrador a la censura», a lo largo de cuyas páginas 
Es cierto que el propio Calderón podría haber dedicado semanas enteras a confeccionar de su mano el propio "original», esmerando su letra que, sin ser detestable, no resulta un prodigio de regularidad y armonía. Pero, para lo que nos interesa, sería incluso indiferente que hubiera sido él mismo quien lo hubiera manufacturado. Aunque la hipótesis es poco verosímil, ello habría conllevado que, de hacerlo, hubiera tardado más tiempo que el que emplearía un copista profesional avezado en la tarea.Y tiempo no era algo que pudiera desperdiciar si quería acelerar la salida de su Primera parte, ya que debía emplearlo en otras funciones en las que nadie podía sustituirle, pues, ante su estreno como autor publicado en un libro, a él no le interesaba aparecer con un volumen reunido a toda prisa, con comedias propias y ajenas, como había hecho Tirso. Por lo tanto, tenía que concentrarse en recuperar el texto de las comedias, que habían salido de su control hacía seis, diez o más años.

Los escritores o poetas no se quedaban con copia de sus textos. El sistema de propiedad literaria era muy diferente al actual y los «derechos de autor» se enajenaban tan pronto como vendían el original (este sí manuscrito autógrafo y firmado) al «autor» o empresario de compañía, y no podían quedarse con copia ${ }^{8}$. Por consiguiente, se les planteaba un serio problema en el momento de planear la edición de un tomo con doce obras. Alguna vez se ha sugerido que, con todo, guardarían borradores o papeles sueltos, pero no parece probable, pues la norma era la contraria y, en el caso de Calderón, que desde 1625 había visto que el permiso para publicar teatro era denegado indefinidamente, quizá para siempre, no se descubre qué razón le llevaría a hacerlo. Además, el análisis de los textos de la Primera parte confirma que ésta no se basó sobre los originales del escritor. Aunque ello ha de ser el objeto principal de este trabajo en relación con El príncipe constante, cabe adelantar que, en general, distan de ser perfectos. No se trata sólo de que menudeen las erratas, atribuibles a descuidos del cajista, sino que la omisión de versos, las estrofas truncas en su estructura regular, las faltas de sentido, las rimas anómalas son mucho más frecuentes de lo esperable y revelan que el original de imprenta no

se insertan imágenes de bastantes hojas de originales efectivamente usados en la imprenta de entonces y se puede encontrar la bibliografia pertinente.

${ }^{8}$ Iglesias Feijoo, 2001. 
fue elaborado sobre copias autógrafas de las versiones definitivas de las comedias. Si estas no obraban en su poder, como era lo esperable, ¿qué pasos tuvo que dar don Pedro para poder preparar la edición?

La respuesta es bastante sencilla: habiendo vendido sus obras a lo largo de quince años a diferentes «autores», era preciso desandar lo andado y volver a ellos para recuperar sus comedias. Sin embargo, este era un proceso más fácil de concebir que de ejecutar. Es muy probable que algunos de los empresarios pudiesen ser renuentes ante la perspectiva de verse perjudicados si se imprimían textos recientes que aún no habían agotado su vida normal sobre las tablas; sin duda para evitarlo, Calderón decidió compilar un conjunto de comedias que no contasen entre las más nuevas, razón por la que cabe fechar todas las de la Primera parte antes de 1630 o 1631. A mayores, era muy posible que determinados «autores» no fuesen fácilmente localizables; alguno podría haber muerto, otros acaso abandonado la actividad teatral y vendido a otra compañía las obras de que eran propietarios, alguno podría haberse marchado a representar a otros lugares, como Italia o Portugal o bien estar de gira por diversas regiones españolas.

En suma, es preciso pensar que su primer tomo de comedias no es exactamente una recolección de las que él podría considerar más representativas o mejores, sino que supone un equilibrio entre ese legítimo deseo y lo que la necesidad le impuso de acudir a la edición de aquellas que habían podido volver a sus manos de entre las escritas antes de 1631. Sin duda, como vimos, algunas ya habían sido editadas a su disgusto, y con otra autoría en la mayor parte de los casos. Así lo revela su hermano José en la dedicatoria del volumen al Condestable de Castilla, cuando alude al "pesar de haber visto impresas algunas dellas antes de ahora, por hallarlas todas erradas, mal corregidas, y muchas que no son suyas en su nombre y otras que lo son en el ajeno" ${ }^{9}$. Es posible que aprovechase algún texto impreso, aunque lo más probable es que recopilase los manuscritos proporcionados por los «autores». Recogidas las copias con cierta premura, Calderón hubo de enfrentarse en ese momento a un nuevo problema.

Ya hemos visto cómo su hermano, hablando sin duda por el propio don Pedro, descubre la precariedad de las ediciones pirateadas («todas erradas»), lo que no es de extrañar si los impresores de Aragón (o

${ }^{9}$ Calderón de la Barca, Comedias, I. Primera parte de Comedias, p. 8. 
de Sevilla) utilizaron medios un tanto fraudulentos para hacerse con las comedias: copias de actores, sobornos a los «papelistas y secretarios cómicos», como dijo una vez Lope de Vega para aludir a quienes sacaban los traslados dentro de la compañía, puros y simples hurtos... Aunque es verdad que el texto de las ediciones previas en algún caso no es inferior al de la propia Parte y permite incluso subsanar errores y lagunas, Calderón pudo verificar no pocas veces que lo que leía no se correspondía con lo que había escrito originariamente. Pero lo mismo le pudo ocurrir con las obras que le llegaron en forma manuscrita. Imaginar que lo que le devolvieron algunos «autores» eran sus propios originales autógrafos se ve desmentido por la ya mencionada falta de perfección de los textos de la Parte. Sin descartar absolutamente que haya podido recuperar alguno, la mayoría serían simples copias, y todos llevarían las marcas de su ajetreada vida a lo largo de seis, ocho o más años de rodar por los corrales, con los cortes, añadidos o variaciones que empresarios y actores hubieran efectuado para adecuarse a las condiciones de cada representación.

Calderón se halló, sin duda, ante textos de calidad muy diferente y, en el momento de prepararse para salir a la luz pública con el primer tomo de sus obras, hubo de detenerse en la revisión de todo el material. En esa labor le ayudaría la memoria, potencia entonces mucho más desarrollada que hoy, pero es imposible pensar que guardara en ella la totalidad de los versos de todas sus comedias. Además, es obvio que, en el momento de pasar la vista sobre obras de años atrás, pudo mostrarse insatisfecho con ciertos pasos o escenas, o ante estrofas o versos aislados, lo que le habría llevado a corregir y retocar todo lo que le pareciera. $\mathrm{Y}$ en ese proceso de revisión las modificaciones pudieron ser de tal calibre que llegara a confeccionar una versión distinta, esto es, lo que calificamos de segunda versión, lo cual todo indica que fue el caso de La vida es sueño.

Ahora bien, ese deseo de depurar los textos chocaba con la urgencia con que quería terminar el volumen para entregarlo al amanuense que lo pusiera en limpio para llevarlo al fin al Consejo de Castilla. No olvidemos que toda esta labor de recolección de las comedias, cotejo de textos, introducción de correcciones, elaboración de segunda versión en algún caso y copia del definitivo "original», que no era precisamente breve, se realizó en un plazo máximo de diez meses, o de seis, si no supo de la concesión de nuevas licencias hasta la 
aparición de la Segunda parte de Tirso. Lo que un análisis de la Primera de Calderón revela, en fin, es que este proceso estuvo marcado por las prisas, que debieron de irse acumulando conforme el trabajo avanzaba. En algún caso es muy posible que tan sólo echara la vista por encima del manuscrito recuperado y diera por bueno un texto poco satisfactorio.

En definitiva, eso es lo que parece haber ocurrido con la obra que cierra el tomo, El príncipe constante, la comedia de texto más defectuoso de las doce, pese a ser teatralmente una de las mejores ${ }^{10}$. Esta introducción ha sido necesaria para enfrentarse a los problemas que plantea y enmarcarlos en términos, ya que no definitivos, al menos susceptibles de una explicación coherente. Y de todo ello se concluye que, pese a todo, parece imposible aceptar la idea, avanzada alguna vez, de que el dramaturgo tuvo muy poco o nada que ver con la edición. Dado que él la promueve, pues solicita para sí el privilegio, no cabe pensar que estuviese movido tan sólo por el deseo de obtener un magro beneficio económico y que en cambio se despreocupara totalmente de las condiciones en que sus textos se editaban. ¿Por qué protestaba entonces la dedicatoria de su hermano José de las ediciones fraudulentas ${ }^{11}$ ?

La lamentable historia del infante de Portugal había sido presentada en los corrales en 1629. Son bien conocidas las protestas de fray Hortensio Félix de Paravicino ante unos versos que lo ridiculizaban y que habían sido introducidos en la comedia para burlarse de su florido estilo, pues en un sermón pronunciado en febrero de ese año ante el rey el predicador había censurado las demasías que don Pedro Calderón y otros cometieron al asaltar el convento de las Trinitarias en persecución de un actor que había herido a su hermano, escandaloso incidente que debió de ocurrir en enero o muy a principios de febrero. No deja de resultar paradójico que el detalle de los hechos y los versos a que luego se alude sean hoy conocidos tan sólo por ha-

${ }^{10}$ En el estudio preliminar a mi edición de la Primera parte (Calderón de la Barca, Comedias, I. Primera parte de Comedias, p. xlii), expreso que la obra «ofrece un estado textual desastroso» (p. xlii), lo que reitera la calificación de Parker en la suya (1938, p. v), como «a very defective text». Sorprendentemente, Porqueras Mayo (1975, p. lxxxiii), afirma que, «sin ser perfecto, lo consideramos bastante normal o aceptable».

${ }^{11}$ Ver de momento, respecto al sentido de la edición de las Partes calderonianas, Paterson, 2001; Fernández Mosquera, 2005; Baczyńska, 2005. 
berlos transcrito de propia mano el mismo ofendido, pues Paravicino dirigió al rey un largo e indignado memorial en que acusaba a Calderón de hereje, blasfemo y reo de alta traición y venía al fin poco menos que a pedir su cabeza.

Lo sucedido fue que Calderón incluyó la burla contra el fraile cuando la obra estaba en ensayos por la compañía del autor Bartolomé Romero, que la estrenó poco después de acabada la cuaresma al volver a abrirse los teatros ${ }^{12}$. Paravicino declara que él mismo copió los versos en cuestión del texto escrito y firmado por don Pedro que obraba en poder del empresario, original que fue finalmente secuestrado por la autoridad. Para mayor escarnio, tras ofrecer el dramaturgo suprimirlos ya el primer día, lo que significa que la protesta fue inmediata, no sólo no lo hizo, sino que insistió en que se mantuvieran al menos cuatro tardes más y aun se pronunciaron tal cual en una representación habida ante el propio rey. No es imposible que éste se hubiese divertido con la alusión, que tampoco era sangrante, pero ante la presentación del furibundo memorial del fraile pasó el asunto a manos del cardenal Trejo, Presidente del Consejo de Castilla, que el 19 de mayo acabó por resolver que, siendo censurable la osadía de Calderón, el trinitario exageraba sin tasa e incluso en su respuesta al rey reprendía con mayor énfasis al denunciante.

De todo ello resulta evidente que el escándalo que corrió por Madrid fue notable, hasta el punto de que, según el propio Paravicino, los pasquines o carteles con que se anunciaban las comedias por los muros de las calles fueron escritos en rojo e incluyeron versos (¿del mismo Calderón?) que anunciaban la sátira incluida en la representación; más aún, según cuenta el ofendido fraile, un sacerdote que también escribía comedias dijo que «las gracias de un bufón vinoso» (términos con que alude al gracioso, personaje que las pronuncia) «hacían valer algo» la obra calderoniana. La afluencia de público debió de ser

12 Calderón parece haberla introducido a última hora en el manuscrito de El príncipe constante. En la resolución del cardenal Trejo, citada luego, se dice que «el verso en que le nombra [a fray Hortensio] está enmendado y añadido, de suerte que es muy verisímil que, cuando la comedia se aprobó por el que las ve, y por el Comisario del Consejo que lo tiene a su cargo, no estaba allí el nombre del padre Hortensio, y lo añadieron después, y parece lo añadido letra del mismo autor de la comedia, siendo suya la del borrador». Para todo este asunto, ver Wilson, 1961, que transcribe los documentos, cuya grafía aquí se normaliza, y Cerdan, 1983. 
masiva y quizás por ello Romero, el «autor», pagó a don Pedro ochocientos reales, suma que parece exceder lo normal en la época. Si a la luz del incidente volvemos la vista a la edición de la Primera parte (fol. 280r), no nos extrañará no hallar ni rastro de la burla contra el predicador; en efecto, tales versos no fueron impresos. Sin embargo, sabemos exactamente dónde estaban situados, y por ello se aclara una ruptura de la regularidad estrófica, parcialmente subsanada si se introducen, como resulta obligado:

BRITO

¡Gracias a Dios que abriles piso y mayos

y en la tierra me voy por donde quiero sin sustos, sin vaivenes ni desmayos! $\mathrm{Y}$ no en el mar adonde, si primero no se consulta un monstruo de madera, que es juez de palo en fin, el más ligero no se puede escapar de una carrera en el mayor peligro. ¡Ah, tierra mía! ¡No muera en agua yo, como no muera tampoco en tierra hasta el postrero día!

ENRIQUE

FERNANDO

ENRIQUE
¿Que escuches este loco?

¡Y que tu pena

sin razón, sin arbitrio y sin consuelo, tanto de ti te priva y te divierte!

El alma traigo de temores llena; echada juzgo contra mí la suerte; desde que de Lisboa salí, sólo imágines he visto de la muerte. Apenas, pues, el berberisco polo...

Los tercetos ofrecen una rima anómala: tras la secuencia correcta $\mathrm{ABA}, \mathrm{BCB}, \mathrm{CDC}$, falta un verso con la tercera rima en -ía (para formar serie con mía y día), otro que presente la tercera rima en -ena (para combinar con pena y llena) y queda suelta la rima en -elo, pues consuelo carece de ninguna correspondencia. La regularidad se recupera a partir de la rima en -erte. Es decir, que existe un corte tras la intervención de Brito, el gracioso. Aquí es justamente donde se producía la pulla contra Paravicino, rescatada de su memorial, que permite restituir casi toda la secuencia métrica (pp. 1071-1072): 
no se puede escapar de una carrera en el mayor peligro. ¡Ah, tierra mía! ¡No muera en agua yo, como no muera tampoco en tierra hasta el postrero día!

FERNANDO

BRITO

ENRIQUE

FERNANDO
¿Qué es eso, Brito?

Una oración se fragua

fúnebre, que es sermón de Berbería: panegírico es que digo al agua y en emponomio horténsico me quejo, porque este enojo, desde que se fragua con ella el vino, me quedó, y ya es viejo.

¿Que escuches este loco?

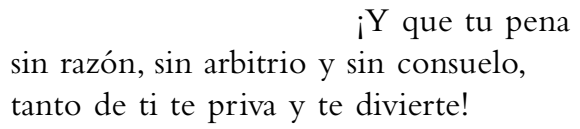

ENRIQUE

La métrica recobra ahora la tercera rima en -ía, pero sigue faltando un verso que combine con pena y llena, y otro con rima en -ejo para formar serie con quejo y viejo, que sustituya el anómalo consuelo, que no rima con nada ${ }^{14}$. Es obvio que a la hora de levantar los versos satíricos y escandalosos del manuscrito se produjo un desorden que ya no se puede sanar, pues no cabe pensar que Calderón, cuando los introdujo con prisa, los hubiera incluido sin respetar el sistema de los tercetos. Con todo, el fragmento que se burla de Paravicino debe ser reproducido al editar la obra, no sólo por su valor histórico, sino también porque recupera lo que los espectadores oyeron cuando la comedia se estrenó, aparte de remediar casi toda la estructura métrica.

Los múltiples defectos del texto en la Primera parte no residen en este punto, que venía obligado por lo que no pasa de ser una intervención de la censura, aunque es curioso que Calderón no se haya esforzado lo más mínimo en restaurar la regularidad de los tercetos al

13 Para el texto que se ofrece se sigue la edición preparada por mí de la Primera parte (2006), con indicación en el texto de la página correspondiente.

14 ¿Acaso oculta un improbable consejo?; así lo edita Parker, 1938, p. 18. 
imprimir la obra, como si deseara que se notase el descosido. A lo largo de los menos de 2800 versos son multitud los que ofrecen hipermetrías o hipometrías, faltas de sentido, errores, al igual que hay muchas estrofas que carecen de regularidad o descubren ausencias, o aparecen, en fin, parlamentos atribuidos a personajes equivocados. No es del caso hacer aquí relación pormenorizada de ejemplos al respecto. Baste señalar que, ya en el primer folio (276r), el segundo verso de la comedia está errado: «mientras de toma de vestir», con un «de» repetido que produce hipermetría y carece de sentido, aunque se trate de una simple errata. Tras el verso cuarto hay un punto, seguido de mayúscula en la palabra inicial del quinto, que rompe la sintaxis. En la página siguiente (fol. 276v), la primera intervención de las moras se atribuye a Fénix, cuando es a ella a quien se dirige. En las dos columnas de esta página podemos hallar versos hipométricos («ni blancura el jazmín» ${ }^{15}$ ); una breve frase ("¿Qué tienes?») atribuida a Zara tiene que ser de Celima, pues Fénix le responde: «Si yo supiera, / ¡ay, Celima!»; una incongruencia por omisión de una negación («Pues puédente divertir / tu tristeza», cuando tiene que ser "Pues no pueden divertir» ${ }^{16}$ ); faltas de sentido y malas lecturas («cual la primavera her-

15 Pudiera argüirse que el verso es correcto si se produce hiato entre «blancura» y «el», pero, aparte de lo forzado del recurso, se destruye el paralelismo con el verso anterior: «ni la púrpura la rosa / ni la blancura el jazmín». Es significativo que la segunda edición de la Parte (VSL) restituya el artículo, pero lo es mucho más que también lo incluyan la edición de Lisboa y varias de las sueltas de que se habla luego.

${ }^{16}$ Aunque aquí no es cuestión de comparar el texto de la comedia con el de su posible primera versión, conservada en un manuscrito de la Biblioteca Nacional de España al que se hace referencia luego, cabe señalar que en ella este verso lo pronunciaba Fénix y rezaba: «no me pueden divertir», mientras que en la Parte inicia una intervención de Zara. Es muy probable que Calderón, al corregir un texto que leía según la primera versión, no acabase de dejar clara la opción definitiva, que debía omitir la primera persona, y el copista que preparó el original lo trasladó mal; en efecto, este no parece error de cajista. Debe señalarse que la intervención que acabamos de indicar como erróneamente atribuida a Zara, en vez de a Celima ("¿Qué tienes?»), en la primera versión la pronunciaba efectivamente Zara, y Fénix contestaba: «Si yo supiera, / ay, mi Zara»; parece que también aquí Calderón debió de olvidar sustituir la abreviatura de su nombre por la de Celima, tal como se escribían los de los personajes que hablan en cada caso, pues tampoco semeja error propio de componedor. 
mosa / labra en estatuas de rosa» debe leerse: «que a la primavera hermosa / labran estatuas de rosa» ${ }^{17}$; "Pues no me puedo alegrar» es en realidad «Pues no me puede alegrar»; "de jardín también procura» es «del jardín también procura»); nuevos cortes sintácticos («Hazte al mar», precedida de punto, es la oración principal de lo que comienza «Pues no pueden divertir»; «Cuando con grandezas sumas», también tras punto, depende de la que se inicia con «Pues no me puede alegrar»; «Su playa la pompa pierde» no puede ir tras punto, pues corta la secuencia sintáctica); errónea separación de palabras, que cambia el sentido: "que soplando en él las bebe» es "que soplando en ellas bebe» ${ }^{18}$.

Todos estos errores, presentes en las dos primeras páginas, de las cuales una solo acoge dieciocho versos y, entre ambas, no alcanzan sino los noventa y uno iniciales (pp. 1057-1059 de nuestra edición), es una leve muestra de los enormes defectos textuales que presenta la comedia en la Primera parte. Por momentos llegaría a pensarse si en los talleres de la imprenta de María de Quiñones la tarea de componer los últimos pliegos del volumen que contienen la obra se hubie-

17 Esta segunda es la lectura de la primera versión, que, como se dirá luego, sólo puede emplearse para depurar el texto cuando coincide con la de la Parte.

18 Sólo la edición de Cantalapiedra y Rodríguez López-Vázquez, 1996, p. 84, mantiene la lectura que se da como errónea, pero ello se explica porque los editores siguen la primera versión que aparece en el manuscrito y que aquí lee igual. El hecho de que haya coincidencia entre QCL (la primera edición de la Parte) y el manuscrito no asegura la fiabilidad de la lectura; aparte de que es muy fácil que en una copia se confunda «en ellas» con «en el las» si hay un mínimo espacio entre las letras, el sentido determina que «en ellas» se refiere a las «flores» mencionadas unos versos antes y reiteradas al momento, mientras que el mantenimiento de «él» hace la expresión incongruente: el céfiro, «soplando en él [tendría que ser 'el mar'], las bebe [las ondas; no podrían ser las flores, pues estas no se dan en el mar]». Es decir: tierra y mar tienen «emulación» entre ellos y compiten espumas y flores; dado que el jardín está «envidioso» de las ondas del mar, quiere imitar su curso, por lo que el céfiro «matices rinde y olores, / que soplando en ellas [las flores] bebe, / y hacen las hojas que mueve / un océano de flores». No se acaba de descubrir qué «matices... y olores» había de beber el céfiro en las ondas del mar. Otra alternativa, que parece inferior, sería que, en la lectura considerada errónea, «en él» se refiera al jardín y en ese caso «las» podría ser asimismo las 'flores'. Se deja de lado en estos versos una variante respecto a "el céfiro", sustituido por "al céfiro" en las ediciones de Parker, p. 3, y Cancelliere, p. 150, pues en ese caso el sujeto de «rinde» es "el jardín", pero el que sopla y bebe sigue siendo el céfiro. Con todo, debe señalarse que los testimonios del siglo XVII mantienen sin excepción «el céfiro». 
se encomendado a un aprendiz sin experiencia para que fuera ejercitándose. Como ello es harto improbable y además imposible de comprobar, resulta más natural creer que el manuscrito con el que se trabajaba contenía la mayor parte de los dislates. Acaso Calderón, apremiado por el deseo de que se terminase cuanto antes el «original» que debía presentar al Consejo para publicar el libro, aceptó la copia de El príncipe constante que llegó a sus manos sin advertir su detestable estado y se contentó con revisarlo por encima e introducir confusamente determinadas correcciones, por lo que el amanuense se limitó a transcribir lo que tenía delante, dando vía libre a un texto muy defectuoso. La última obra del volumen gozó, pues, de una atención muy diferente de la que había tenido la primera, La vida es sueño.

Sea de ello lo que fuere, el problema que se plantea en el momento de realizar hoy la edición es cómo resolver tantos lugares dañados. De muy poco sirven al efecto las reediciones de la Primera parte impresas en vida de Calderón (VSL,VS), pues, aunque salvan algunas erratas, dejan intactos la mayor parte de los problemas, cosa lógica si tenemos en cuenta que el dramaturgo no corrigió esas nuevas ediciones de la Parte. Contamos con la edición póstuma de Vera Tassis, que salva bastantes problemas, a veces quizá con la consulta de algún otro testimonio imposible de precisar, pero, como era de esperar, el buen juicio crítico del amigo de Calderón se dedicó también a remendar de su propio caletre lo que veía disparatado, y desde luego aquí tuvo ancho campo para ejercer su ingenio. Sin embargo, sus soluciones no son de Calderón o, por mejor decir, es imposible verificar si en algún caso coincidirían con las originales. Por lo tanto, editar sin más la versión de Vera Tassis supone asumir que se elige una obra de Calderón-Vera, opción que no parece muy defendible.

¿Qué hacer? Como editores, resulta igualmente repugnante mantener un texto que sabemos errado, pero no cabe actuar ope ingenii a cada paso, pues se correría el riesgo de sustituir una obra de CalderónVera por otra no más plausible de Calderón-el editor. Es inaceptable conservar lo que a todas luces carece de sentido, pero nuestra capacidad de acción está limitada. Por fortuna, la crítica textual proporciona el camino: lo primero es atender a todos los testimonios existentes, principio siempre elemental para la resolución de los problemas; además, las ediciones impresas de la comedia en el siglo XVII antes de 
Vera Tassis no son escasas. Pero lo sorprendente es que apenas se hayan tenido en cuenta hasta ahora.

El primer testigo no se trata de un texto impreso, sino manuscrito. Por desgracia, a la vez que ilumina muchos pasos, añade una complejidad suplementaria, pues encierra una versión diferente de la comedia. No es este el momento para dilucidar si el manuscrito 15159 de la Biblioteca Nacional española transmite una primera versión de Calderón o sólo recoge los arreglos de una compañía de cómicos para una representación concreta; Wilson lo despreciaba como una refundición tardía ${ }^{19}$, mientras Cantalapiedra y Rodríguez López-Vázquez lo toman como base de su edición ${ }^{20}$. Sea como fuere, es seguro que se trata de una versión diferente, que altera casi por completo el papel del gracioso e incluye otras variaciones de diversa entidad. Por eso hay que extremar el cuidado y no fundir ambos textos; aun en el caso de que fuese auténticamente calderoniana - lo que, pese al dicterio de Wilson no es por principio imposible ${ }^{21}$, aunque el manuscrito pueda incluir también intrusiones de otra mano-, realizaríamos entonces una taracea para crear una obra que nunca existió. Por ello, sólo deben atenderse las soluciones que el manuscrito proporciona para sanar pasajes dañados que sean coincidentes con el texto de la Primera parte. Aun así, debe aceptarse que este testimonio arroja luz sobre no pocos momentos y resulta una ayuda muy apreciable.

Aparte de esta versión, existen otros lugares adonde acudir; se trata de varias ediciones impresas, la primera de las cuales es la única fechada, pues está incluida en el volumen Doce comedias las más grandiosas que hasta ahora han salido, de los mejores, y más insignes poetas. Cuarta

${ }^{19}$ Wilson, 1961b, p. 786: «To attribute to Calderón such stuff as this is clearly absurd».

${ }^{20} \mathrm{La}$ verdad es que, aunque los editores alegan que su elección «no es, en modo alguno, arbitraria ni injustificada» (Cantalapiedra y Rodríguez López-Vázquez, 1996, p. 68), sólo apuntan que "consta de unos doscientos versos más que las ediciones impresas» y que Valbuena Briones, en su edición de la Primera parte (1974) «observó la perfección de dicho manuscrito", cosa que en ningún sitio afirma este último, sino que lo usa para corregir lugares concretos.

${ }^{21}$ Hoy empezamos a saber mucho más de la existencia de dobles versiones por parte de Calderón, por lo que una respuesta precisa para el caso de El príncipe constante debe ser obtenida tras considerar el conjunto de comedias que están en el mismo caso. 
parte (Lisboa, 1652), donde también aparece Lances de amor y fortuna. El texto de nuestra obra tampoco es perfecto, pero pertenece a la misma rama que la Parte de 1636 (es decir, no se emparenta con la del manuscrito) y permite resolver alguno de sus problemas ${ }^{22}$. Así, el v. 180, que en QCL (fol. 277v / p. 1062) dice «vuelto el árabe idioma», lo que no hace mucho sentido (el manuscrito aquí lee "que vuelta en hebreo idioma», con falta o trastrueque de algunos versos), se restaura bien: «vuelto en el árabe idioma» (Lisboa, fol. 2r) ${ }^{23}$. Al final de la primera jornada, v. 963 (QCL, fol. 284r / p. 1085), hallamos un verso corto: «si con gran silencio el miedo vano», que se corrige parcialmente: «sino con gran silencio el miedo vano» (Lisboa, fol. 7v), lo que además confirma la mejor lectura del manuscrito en este paso, que es la que debe ser preferida: «sino con gran silencio en miedo vano».

La jornada segunda se inicia con décimas, la segunda de las cuales en QCL (fol. 284v / p. 1086) tiene nueve versos:

\author{
Lisonjera, libre, ingrata, \\ dulce, suave una fuente \\ hizo apacible corriente \\ de cristal y undosa plata. \\ Lisonjera se desata \\ porque hablaba y no sentía,
}

22 Aunque este impreso no es desconocido, pues lo citan en sus ediciones tanto Porqueras como Cantalapiedra y Rodríguez López-Vázquez, estos últimos con listado de variantes al final, nadie parece haber advertido su importancia para la depuración del texto de la comedia. Cancelliere no lo menciona.

23 Entiéndase la frase: 'el nombre de Ceido - Ceuta en hebreo- vuelto o traducido en árabe quiere decir hermosura'. He de confesar la perplejidad, compartida con muchos editores, al elegir la lectura de QCL en un verso inmediatamente anterior: «está a la boca / del Preto Eurelio fundada». Porqueras, p. 12, y Cancelliere, p. 156, señalan lo significativo de que todas las ediciones del XVII coincidan al leer así, que es lo que hago yo también en mi edición, y que Vera Tassis no lo haya corregido. Con todo, no es imposible que lo que escribió Calderón hubiera sido «a la boca / del Freto Hercúleo», como corrigen otros editores. Covarrubias, p. 515, dice en la voz Ceuta: «Lugar de África, ad fretum Gaditanum», y en la entrada Gibraltar, p. 971, aclara que el estrecho de este nombre «es dicho por los antiguos fretum Herculeum, fretum Gaditanum, fretum Calpes». Sin embargo, el no hallar hasta ahora muestras de la castellanización de fretum en «freto» me ha inclinado a ser conservador y no introducir la enmienda. 
suave porque fingía,

dulce porque murmuraba, ingrata porque corría.

No sólo la métrica descubre el error, sino que también se rompe la correlación, pues uno de los cinco adjetivos iniciales carece de desarrollo. El manuscrito no ofrece aquí correspondencia, pero la edición de Lisboa (fol. $7 \mathrm{v}$ ) resuelve el problema; en ella, los seis últimos versos dicen así:

\author{
Lisonjera se desata \\ porque hablaba y no sentía, \\ suave porque fingía, \\ libre porque murmuraba, \\ dulce porque lisonjeaba, \\ ingrata porque corría.
}

Cabría pensar, en este como en otros lugares, que la edición de Lisboa pudo haber sido preparada por un corrector especialmente cuidadoso, cual un antecedente de Vera Tassis, que se dedicó a restaurar de su caletre lo que le parecía errado. Aparte de que ello queda fuera de los usos de la imprenta de entonces, no porque no se corrigiera lo más evidente, sino porque no había criterios ecdóticos como los actuales, siguen presentes en esta edición muchas cosas sin corregir, lo que no ocurriría si detrás estuviese un erudito preparador de la edición. La prueba de que Lisboa sigue un texto emparentado con QCL, pero derivado de una rama independiente con mejores lecturas (algunas, como ya vimos, conectadas con el manuscrito, lo que demuestra que remontan a un antecedente común) la ofrece precisamente este ejemplo, porque la misma décima, con mínimas variantes no significativas al caso, la incluye Calderón en una obra de su Segunda parte, Amor, honor y poder (fol. 229r), y ahí, por supuesto, figura el verso desaparecido en QCL por fusión de dos de los originales.

Algo similar ocurre poco después, cuando se acaban las décimas y comienza una escena en redondillas, la primera de las cuales en QCL (fol. 285r / p. 1088) tiene sólo tres versos: 
Desde aquel jardín te vimos

andar a caza, Fernando,

$\mathrm{y}$ todos juntos venimos.

El manuscrito incluye aquí como tercer verso «nuestro trabajo dejando", lo que completa la estrofa; pero Lisboa (fol. 8r), también en tercer lugar, lee: «donde estamos trabajando", lo que parece preferible dada la mayor cercanía que en conjunto presenta con el que parece haber elegido Calderón, es decir, al ser de la misma rama: aunque se aceptase que la versión manuscrita es de Calderón, la elegida para la Primera parte fue la otra, a cuya rama pertenecen tanto QCL como Lisboa. Es de señalar que Vera edita exactamente ese mismo verso, aunque lo ubica en segundo lugar, lo que parece probar que se ayudaba de algún texto que ya lo recogía.

Otro ejemplo aparece poco después; siguen las redondillas y de improviso, un octosílabo queda con tres sílabas y falto de rima: «Tu vista / hace nuestra esclavitud / dichosa» (QCL, fol. 285v / p. 1089). Vera, siempre con buen sentido, completa el verso: «Señor, tu vida y salud» ${ }^{24}$. Pero en Lisboa leemos (fol. 8r): «Verte con vida y salud», lo que parece preferible a cualquier otra opción. Cabría aducir aún otros pasajes en el mismo sentido para confirmar cómo la edición de Lisboa ofrece un texto que, siendo cercano al de la Primera parte, no depende de él, pues colma varias de sus lagunas y corrige otros errores.

Sin embargo, para concluir, debe señalarse aún la existencia de otros testimonios que han de ser atendidos para fijar el texto de El príncipe constante en una edición crítica y que no han llamado la atención de nadie hasta ahora. En el complicado volumen que forma la Sexta parte de comedias nuevas escogidas de los mejores ingenios se incluye nuestra comedia. Aunque, en principio, hay dos tomos de portada, contenido y fecha diferente, uno que se dice editado en Zaragoza en 1653 y otro en la misma ciudad en 1654, nos centraremos en este último - pues el otro no la imprime-; debe señalarse que los escasos estudiosos que la mencionan a propósito de la obra que nos interesa consideran que se trata de una única edición. Nada menos exacto. Atendamos en primer lugar a los ejemplares de esta Sexta parte de escogidas existentes en

24 Parker, p. 38, edita: «Señor, tu vista y salud», y le sigue Cancelliere, p. 200. 
las Bibliotecas de Viena, Bodleian de Oxford y Florencia ${ }^{25}$, que están formados por un conjunto de sueltas. Una de ellas es la obra que nos interesa y se trata en los volúmenes de estas bibliotecas de tres ejemplares idénticos de la misma impresión, que lleva el título El mártir de Portugal y el nombre de don Pedro Calderón de la Barca en la portada $^{26}$. El texto depende de la primera edición de la Primera parte, es decir, de QCL, con alguna corrección de erratas e introducción de otras y puede ser de la fecha que declara el volumen, esto es, 1654; desde luego no sigue ninguna de las dos reediciones de la parte (VSL y VS). Tiene escaso interés.

Existen además otros tomos facticios que dicen ser también volúmenes de esa Sexta parte y que incluyen sueltas diferentes de la anterior - todas, la precedente y las que siguen, sin indicación de lugar, impresor ni fecha-, por lo que es preciso revisar cuantos ejemplares se puedan localizar de ese volumen de Escogidas por si se descubren nuevas sueltas desconocidas. Hasta el momento puede afirmarse ya que la que figura en un ejemplar falsificado de la Sexta parte de la Biblioteca Universitaria de Friburgo, que fue de Salvá y de Schaeffer, es distinta. El volumen se formó por agrupación de otro conjunto de comedias sueltas, poniéndole una portada remendada, pero, como sucede siempre en tales casos, lo trascendente no es que puedan hallar acogida en el tomo ejemplares de fechas muy diversas, sino la rareza y valor textual de cada una de ellas ${ }^{27}$. La que nos importa aquí lleva el título El príncipe constante y el nombre del autor en portada y presenta el notable interés de estar vinculada al texto de la edición antes mencionada de Lisboa; así, todas las lecturas que hemos dado como ejemplos de la edición lisboeta están igualmente en esta suelta.

Finalmente, en la British Library londinense, en la Biblioteca Nacional en Madrid y en la Public Libray de Boston hay tres volúme-

${ }^{25}$ Hay aún —o más bien hubo- otro ejemplar en la Landesbibliothek de Berlín, que ha desaparecido (Hämel, 1920, p. 627). Ver de momento para todo esto el análisis detallado de Profeti, 1976. Ahí queda claro que el único ejemplar que parece haberse conservado de la edición del año 1653 está también en Viena. El profesor Cruickshank y yo mismo estamos intentando clarificar algo más los problemas de esta extraña Parte.

26 Entiéndase: en la portada de la suelta, es decir, en su primera página. El índice del volumen comete el error de atribuir la obra a don Francisco de Rojas.

${ }^{27}$ Ver para este ejemplar Stark, 2003, vol. I, pp. xlii, y p. 572, núm. 1019. 
nes casi idénticos que pretenden ser también la Parte sexta de escogi$d a s^{28}$; ahí figura otra suelta (son ejemplares de la misma impresión), titulada El príncipe constante, sin nombre de autor en portada, pero sí en los titulillos de las páginas de la derecha. El texto deriva de la Primera parte de Calderón, pero no de la primera edición (QCL), ni de la segunda (VSL), sino de la tercera (VS): omite el v. 940 ("pero dile a Duarte que en llevalle», p. 1084), que también falta en VS, y la sigue, por ejemplo, en varias variantes acumuladas al final de la comedia ( $p$. 1139): «Haré depósitos graves / de vuestro sagrado cuerpo» se convierte tanto en VS como en la suelta en "haré depósito grave / de un cadáver tan invicto»; "por el amistad que sé» se transforma en "por la amistad que yo sé»; "ved vuestro santo y llevalde» pasa a ser «ved vuestro dueño y llevadle»; "Todos es bien te acompañen» se cambia en «le acompañen», y unas cuantas más, aquí y en otros lugares de la obra. Como es sabido, VS se imprimió en torno a $1670-1671^{29}$, por lo que la suelta ha de ser posterior.

Queda, en fin, por señalar que en la ya citada biblioteca de Friburgo se guarda aún otra suelta diferente a todas las anteriores, pero que ya no está vinculada a la Parte sexta de escogidas, titulada asimismo El príncipe constante, pero sin el nombre de Calderón en la portada, sino sólo en los titulillos ${ }^{30}$. Está estrechamente emparentada con la anterior, depende también de VS y ofrece las mismas lecturas que hemos selec-

28 El ejemplar madrileño ( $\mathrm{R}$ 22659), carece de portada, pero tiene una manuscrita que lo atribuye erróneamente a 1649 . Se trata también de un conjunto de sueltas, que editan las mismas obras que la otra Sexta parte mencionada (Viena, Oxford y Florencia), pero la portada y las sueltas que incluyen son diferentes. Sin embargo, tampoco los tomos de Londres, Madrid y Boston son del todo iguales; los tres recogen las mismas sueltas en diez de las comedias, pero con Obligados y ofendidos coinciden Londres y Bostón, mientras Madrid incluye una suelta diferente, y con La banda y la flor coinciden Madrid y Londres, pero Boston tiene una suelta distinta. Parecen más tardías (quizá de los años 70 del xviI; ver lo señalado luego en el texto) y debidas a distintos impresores. ¿Pertenecerá a esta serie el ejemplar perdido de la Sexta parte de Berlín?

${ }^{29}$ Cruickshank, 1973.

${ }^{30}$ Ver Stark, 2003, vol. I, p. 574, núm. 1020; en la página anterior, la 573, se reproduce la portada. En realidad, en Friburgo hay aún otra suelta, cabe suponer que más tardía, que lleva en la portada el número 280 y pertenece a la colección Jardín ameno, parte XXIV, pero por los dos versos finales no parece derivar del texto de Vera Tassis (Stark, 2003, vol. I, p. 574, núm. 1021). 
cionado, pero al tener menos erratas propias que la precedente, cabe pensar que ambas deriven independientemente de VS, o que esta última suelta es intermedia entre VS y la antes considerada. Debe de ser también, por lo tanto, de los años setenta o posterior.

En suma, hasta ahora, aparte de la edición de Lisboa, están localizadas cuatro sueltas que siguen un texto que no depende deVera Tassis, lo que hace presumir que son anteriores. Unas resultan más interesantes que otras, sin duda, pero todas deben ser colacionadas para desechar sin más las que carezcan de interés y atender, en cambio, a aquellas que pueden depender de un testimonio hoy perdido que remonte a lo que solemos calificar de ramas altas del estema. Ha de señalarse, además, aunque ya no cabe ocuparse aquí de ello, que alguna de las sueltas tiene curiosas lecturas ocasionales coincidentes con la versión que nos transmite el manuscrito, lo que lleva a reforzar la idea de que Calderón fue su autor. Por lo tanto, queda mucho trabajo por delante hasta el día en que pueda contarse con la edición crítica de una de sus mejores comedias. A ponerlo de relieve se han destinado estas páginas, que sólo han espumado algunos ejemplos significativos, simples calas de muestra que deben tener continuación por parte de quien acometa tan necesaria tarea. Sólo cabe sugerir, para terminar, que, ante el evidente deterioro del texto, tal editor se verá obligado a arriesgar, ope ingenii, un poco más de lo que suele ser habitual en estas faenas. 


\section{BiBLIOGRAFÍA}

Ediciones de la Primera parte de comedias de Calderón:

Valbuena Briones, Á., Madrid, 2 vols., CSIC, 1974.

Calderón de la Barca, P., Comedias, I. Primera parte de Comedias, ed. L. Iglesias Feijoo, Madrid, Biblioteca Castro, 2006.

CL, Primera parte, Madrid, María de Quiñones, 1936.

VS, Primera parte, Madrid, Viuda de Juan Sánchez, «1640» [1670].

Ediciones de El príncipe constante:

Parker, A. A., Cambridge, Cambridge University Press, 1938; se cita por la reedición de 1968 .

Porqueras Mayo, A., Madrid, Espasa Calpe, 1975.

Cantalapiedra, F. y A. Rodríguez López-VÁzquez, Madrid, Cátedra, 1996.

Cancelliere, E., Madrid, Biblioteca Nueva, 2000.

Otros textos teatrales:

Tirso De Molina, Obras completas, IV (Segunda parte de las comedias), ed. M. ${ }^{\text {a }}$ P. Palomo, Madrid, Biblioteca Castro, 2005.

Estudios citados:

Baczyńska, B., «Pedro Calderón de la Barca y su Primera y Segunda parte. Una hipótesis de trabajo", en Actas del Congreso "El Siglo de Oro en el nuevo milenio", ed. C. Mata y M. Zugasti, Pamplona, EunsA, 2005, vol. I, pp. 249261.

Cerdan, F., «Paravicino y Calderón: religión, teatro y cultismo en el Madrid de 1629", en Calderón. Actas del Congreso Internacional sobre Calderón y el Teatro Español del Siglo de Oro, ed. L. García Lorenzo, Madrid, CSIC, 1983, vol. III, pp. 1259-1269.

Cotarelo y Mori, E., ed., Comedias de Tirso de Molina, Madrid, NBAE, I, 1906.

Covarrubias Horozco, S. de, Tesoro de la lengua castellana o española, ed. I. Arellano y R. Zafra, Madrid, Iberoamericana / Vervuert, 2006.

Cruickshank, D. W., "Calderón's Primera and Tercera partes: the reprints of '1640' and '1664'», en Wilson, E. M. y D. W. Cruickshank, The Textual Criticism of Calderón's Comedias, vol. I de Pedro Calderón de la Barca, Comedias, A facsimile edition prepared by D. W. Cruickshank and J. E. Varey, Westmead, Farnborough, Hants, Gregg-London, Tamesis, 1973.

Fernández Mosquera, S., «Defensa e ilustración de la Segunda parte (1637) de Calderón de la Barca», en Estudios de Teatro Español y Novohispano. Asociación Internacional de Teatro Español y Novohispano de los Siglos de Oro, 
XI Congreso, ed. M. Romanos, F. Calvo, X. González, Buenos Aires, Universidad de Buenos Aires, 2005, pp. 303-325.

Hämel, A., "Beiträge zur Lope de Vega-Bibliographie», Zeitschrift für Romanische Philologie, XL, 1920, pp. 623-633.

Iglesias Feijoo, L., «Los textos de Calderón: las comedias», en Calderón desde el 2000 (Simposio Internacional Complutense), ed. J. M. Díez Borque, Madrid, Ollero y Ramos, 2001, pp. 77-108.

Moll, J., «Diez años sin licencias para imprimir comedias y novelas en los reinos de Castilla: 1625-1634», Boletín de la Real Academia Española, 54, 1974, pp. 97-103.

- «De la continuación de las partes de comedias de Lope de Vega a las partes colectivas", en Homenaje a Alonso Zamora Vicente, Madrid, Castalia, vol. III, 2, 1992, pp. 199-211.

Paterson, A. K. G., «La socialización de los textos de Calderón. El legado de don Juan de Vera Tassis y don Pedro de Pando y Mier», en Calderón: Innovación y legado. Actas selectas del IX Congreso de la Asociación Internacional de Teatro Español y Novohispano de los Siglos de Oro, ed. I. Arellano y G.Vega García-Luengos, New York, Peter Lang, 2001, pp. 17-29.

Profeti, M. G., «Un enigma bibliográfico: la Parte VI de comedias nuevas Escogidas", Annali della Facoltà di Economia e Commercio, Verona, 1976, pp. 5-18.

Reyes Gómez, F. de los, El libro en España y América. Legislación y censura (siglos XV-XVIII), Madrid, Arco, 2000, 2 vols.

Rico, F., El texto del "Quijote». Preliminares a una ecdótica del Siglo de Oro, Barcelona, Destino, 2005 [2006].

StARк, E., Die Sammlung spanischer comedias in der Universitätsbibliothek Freiburg, Kassel, Reichenberger, 2003, 2 vols.

Wilson, E. M., «Fray Hortensio Paravicino's Protest against El príncipe constante», Ibérida, 6, 1961, pp. 245-266 (reimpreso en separata, 1966).

- "An Early Rehash of Calderón's El príncipe constante», Modern Language Notes, 76, 1961b, pp. 785-794. 